Canadian

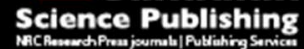

Canadian Journal of Chemistry Revue canadienne de chimie

\title{
The application of XANES for the examination of silver, gold, mercury, and sulfur on the daguerreotype surface
}

\begin{tabular}{|c|c|}
\hline Journal: & Canadian Journal of Chemistry \\
\hline Manuscript ID & cjc-2017-0062.R1 \\
\hline Manuscript Type: & Article \\
\hline Date Submitted by the Author: & 04-May-2017 \\
\hline Complete List of Authors: & $\begin{array}{l}\text { Kozachuk, Madalena; The University of Western Ontario, Chemistry } \\
\text { Martin, Ron; Department of Chemistry } \\
\text { Sham, Tsun-Kong; Department of Chemistry, } \\
\text { Robinson, Mike; Century Darkroom } \\
\text { Nelson, Andrew; University of Western Ontario }\end{array}$ \\
\hline $\begin{array}{r}\text { Is the invited manuscript for } \\
\text { consideration in a Special } \\
\text { Issue?: }\end{array}$ & TK Sham \\
\hline Keyword: & $\begin{array}{l}\text { Daguerreotypes, X-ray absorption spectroscopy, Surface metrology, } \\
\text { Surface topology }\end{array}$ \\
\hline
\end{tabular}


1

32

The application of XANES for the examination of silver, gold, mercury, and sulfur on the daguerreotype surface

M.S. Kozachuk ${ }^{1 *}$; R.R. Martin ${ }^{1}$; T.K. Sham ${ }^{1 *}$; M. Robinson ${ }^{2}$; A.J. Nelson ${ }^{3}$

1. Western University, The Department of Chemistry, 1151 Richmond Street, London, Ontario, N6A 5B7, Canada

2. Century Darkroom, 245 Carlaw Avenue, Studio 502, Toronto, Ontario, M4M 2S1, Canada

3. Western University, The Department of Anthropology, 1151 Richmond Street, London, Ontario, N6A 5B7, Canada

*Corresponding Author: tel: 1-(519) 661-2111 ext. 86341; fax: 1-519-661-3022; email: mkozachu@uwo.ca (M.S. Kozachuk); tsham@uwo.ca (T.K. Sham)

8

9

.

1

22

3

4

5

6

7

8

29

30

1


33 Abstract X-ray absorption near edge structure (XANES) spectroscopy was used to study

34 a freshly prepared reference daguerreotype surface as the first step in devising improved

35 methods for the conservation of these important historic artifacts. The results are

36 consistent with the formation of alloy image particles. Inter-diffusion of gold and silver

37 has led to the development of a silver-gold alloy; the composition varies with depth. The

38 amount of gold appeared to be elevated in the highlighted regions of the image while

39 shadow regions have lower levels of gold on the surface. The apparent increase in gold

40 within the highlight region may be due to the larger surface area presented by an array of

41 small image particles. The mercury used to develop the daguerreian image showed no

42 evidence of oxidation while a mercury-silver alloy was detected. Sulfur based

43 contaminants are also detected. The implications of these findings are discussed.

44

45 KEYWORDS: Daguerreotypes, X-ray absorption spectroscopy, Surface metrology,

46 Surface topology

47

48

49

50

51

52

53

54

55

56 


\section{Graphic Abstract}
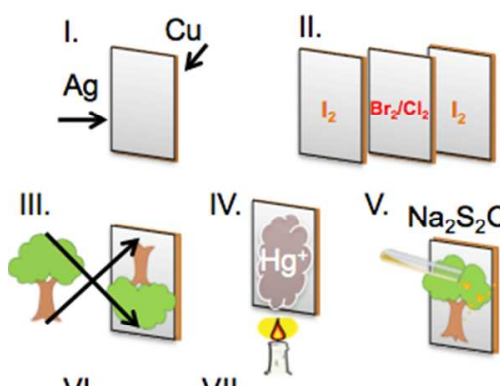

V. $\mathrm{Na}_{2} \mathrm{~S}_{2} \mathrm{O}_{3}$

VI.

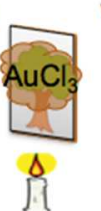

VII.


كُ ك


I. Polishing
II. Sensitization
III. Exposure
IV. Development
V. Fixing
VI. Gilding
VII. Wash

59

60

61

62

63

64

65

66

67

68

69

70

71

72

73

74 


\section{Introduction}

76 Invented in 1839 by Louie-Jacques-Mandé Daguerre, the daguerreotype process was used

77 throughout Europe and North America for a span of approximately 25 years. The process

78 consists of rendering a silver surface photosensitive by reaction with iodine vapour. After

79 light exposure the image is developed with mercury vapour. Later refinements included

80 gilding to enhance image contrast $[1,2]$. The appearance of the daguerreotype image is

81 the result of the interaction (reflection and scattering) of light with image particles on the

82 surface, formed when the photosensitive plate is exposed to light. Regions that were

83 subjected to bright exposure (i.e., highlight regions) produced image particles of

84 relatively uniform structure and density. Portions of the plate that received little to no

85 exposure (i.e. shadow and dark regions) exhibited image particles with variable size,

86 shape and surface density [3a]. This variation in particle density and shape produce the

87 great range of gray tones that typify daguerreotypes.

88 Daguerreotypes are prone to tarnish, fogging, white and blue-tinted haze, and black

89 spots termed "daguerreian measles" [3b] that form as a result of reactions leading to the

90 formation of silver compounds including oxides, chlorides, and sulfides, respectively [4].

91 Sulfur and chlorine are the two elements generally associated with daguerreotype image

92 deterioration in the forms of silver sulfide [5] and silver chloride [6]. The composition of

93 such tarnish has been analyzed using techniques such as diffuse reflectance spectroscopy

94 [7], confocal microscopy [4,8], laser induced breakdown spectroscopy [9], laser ablation

95 mass spectrometry [10], X-ray fluorescence spectroscopy (XRF) [1], two dimensional

96 scanning electron microscopy (SEM) and three-dimensional focused ion beam scanning

97 electron microscopy (FIB-SEM) [2]. These techniques have furthered the understanding

98 of the photo-physico-chemical reactions involved in the formation of the daguerreotype 
99 image as well as the nature of the tarnish formed on these surfaces. This information is 100 important for the conservation, preservation, storage, and display of these artifacts.

101 The research undertaken here used synchrotron radiation analysis, particularly its X-ray 102 absorption near edge structure (XANES) spectroscopy capabilities, to characterize the 103 chemical environment of the elements on the daguerreotype surface. XANES measures 104 the modulation of the absorption coefficient above an absorption edge when the 105 absorbing atom is placed in a chemical environment; the photoelectron, which is 106 produced by the X-rays, will sample the surrounding atoms in the vicinity of the 107 absorbing atom, bring the information back via back scattering as the X-ray energy 108 increases above the absorption threshold. The result is a XANES spectrum that shows the 109 edge jump (threshold) and resonances resulting from transitions to electronic states that 110 are bound, quasi bound (multiple scattering) and in the continuum (EXAFS), which is set 111 up by the molecular potential of the surrounding atoms. This absorption technique, which

112 is elementally and chemically sensitive, at the resolution provided by the synchrotron

113 source, will provide new information regarding the chemical speciation of the elements

114 of interest on the daguerreian plate. This is the first step in devising a strategy for the

115 conservation of these artifacts. Owing to the chemical composition of the daguerreotype

116 plate, the elements of interest for this study are silver, gold, mercury, and sulfur.

\section{Materials and methods}

118 The daguerreotype plate $(5 \times 1 \mathrm{~cm})$ used in this research (Figure 1) was prepared at 119 Century Darkroom, Toronto (Daguerreotypist, Mike Robinson) using the process 120 described by Humphrey [11]. Once the silver coated copper plate was polished to a 121 mirror finish, the plate was historically exposed to iodine vapour. Bromine and chlorine 122 were later added to the photosensitizing process, which reduced the exposure time from a 
123 few minutes to a few seconds. Once the plate was exposed to the image of interest, the

124 daguerreotype was developed with mercury vapour heated to $70{ }^{\circ} \mathrm{C}$. A sodium thiosulfate

125 wash removed any residual silver halide. The final step involved pouring a gold-chloride-

126 sodium thiosulfate solution over the plate, which was heated from below, depositing gold

127 on the image surface $[1,2,11]$. The range of tones on these test plate is representative of

128 the tones observed on historical daguerreian artifacts. All reported XANES spectra were

129 taken at the labeled locations on the daguerreian test plate (A1: dark region; A2: mid-tone 130 region; A3: bright region).

131 Three separate beamlines at the Canadian Light Source (CLS) were used to collect the 132 absorption data: SXRMB, VESPERS, and HXMA (Table 1). The beamlines were 133 selected as their respective energy ranges corresponded to the absorption edges of the 134 elements of interest (silver, gold, mercury, and sulfur). On the daguerreotype test plate, 135 SXRMB was utilized to collect the silver (Ag) $\mathrm{L}_{3}$-edge XANES. The beam was 136 monochromatized by a $\mathrm{Si}(111)$ double crystal monochromator and XANES were 137 recorded in the fluorescence yield (FLY) mode using a 13-element Ge detector situated at $13845^{\circ}$ with respect to the sample stage. Spectra were collected from $3,331 \mathrm{eV}$ to $3,411 \mathrm{eV}$ 139 using a $2.00 \mathrm{eV}$ step size before, a $0.20 \mathrm{eV}$ step size at, and a $0.75 \mathrm{eV}$ step size after the $140 \mathrm{~L}_{3}$ absorption edge region. Larger step sizes before the edge are chosen so that 141 appropriate background correction can be conducted; a smaller step size is used at the 142 edge to optimize the quality of the data. Step size is chosen based on monochromator and 143 slit resolution. The SXRMB line was also used to collect the sulfur (S) K-edge over an 144 energy range of $2,454 \mathrm{eV}$ to $2,534 \mathrm{eV}$ with a $2.00 \mathrm{eV}$ step size before, a $0.20 \mathrm{eV}$ step size 145 at, and a $0.75 \mathrm{eV}$ step size after the absorption edge. The size of the beam on the sample 146 was $1 \mathrm{~mm}$ (vertical) x $4 \mathrm{~mm}$ (horizontal) in both measurements. 
The gold $(\mathrm{Au})$ and mercury $(\mathrm{Hg}) \mathrm{L}_{3}$-edges were initially examined on the VESPERS

148 beamline using XRF with a microbeam using $\mathrm{KB}$ mirrors. The $\mathrm{Au} \mathrm{L}_{3}$-edge XANES 149 spectra were collected from $11,759 \mathrm{eV}$ to $12,150 \mathrm{eV}$ with a step size of $10.00 \mathrm{eV}$ before, 150 a $0.50 \mathrm{eV}$ step size at, and a $0.05 \mathrm{eV}$ step size after the absorption region. The $\mathrm{Hg} \mathrm{L}_{3}$-edge 151 was collected over an energy range of $12,124 \mathrm{eV}$ to $12,400 \mathrm{eV}$ with a step size of 10.00 $152 \mathrm{eV}$ before, a $0.50 \mathrm{eV}$ step size at, and a $0.05 \mathrm{eV}$ step size after the absorption region. For 153 the $\mathrm{Hg}$ standard, an aqueous suspension of elemental $\mathrm{Hg}$ collected in FLY was utilized. 154 The preparation for this standard is outlined in detail elsewhere [12].

155 A series of Ag-Au alloys (Table 2), whose preparation is outlined in Bzowski et al. 156 [13], were also analyzed at the CLS using XANES as standards for comparison with the 157 daguerreotype test plate. The $\mathrm{Ag} \mathrm{L}_{3}$-edge was collected at the SXRMB line under the 158 same conditions described above. The $\mathrm{Au} \mathrm{L}_{3}$-edge was analyzed at the HXMA beamline 159 that focuses the beam with a liquid nitrogen cooled double crystal $\operatorname{Si}(111)$ 160 monochromator (Kohzu CMJ-1). Further collimation is achieved by using a $1.15 \mathrm{~m}$ long 161 water-cooled silicon toroidal focusing mirror. The resulting beam size was $1 \mathrm{~mm}$ 162 (vertical) x $10 \mathrm{~mm}$ (horizontal).

163 The Athena software package [14] was used to calibrate, background subtract, 164 normalize, and average all spectra. The true inflection point at the edge was determined 165 by taking the first derivative of each spectrum as well as setting the tangent slope to zero 166 in the second derivative spectrum following the procedure outlined by Ravel [15]. These 167 first derivative inflections were 3,351 eV, 11,919 eV, 12,284 eV, and 2,472 eV for the Ag $168 \mathrm{~L}_{3}$-edge, $\mathrm{Au} \mathrm{L} \mathrm{L}_{3}$-edge, $\mathrm{Hg} \mathrm{L}_{3}$-edge, and $\mathrm{S} \mathrm{K}$-edge, respectively. A first-order polynomial 169 was fit to the pre- and post-edges of the spectra along with normalizing the edge-jump of 
170 each spectrum to one. A linear combination fit analysis was also performed when

171 appropriate.

\section{$172 \quad 3$ Results and discussion}

\section{$173 \quad 3.1$ Silver}

174 The $\mathrm{Ag} \mathrm{L}_{3}$-edge XANES (edge jump located at 3,351 eV) is shown in Figure 2. The 175 oscillation magnitude relative to a smooth background is compared to the alloy standards; 176 in general, the magnitude is sensitive to the scattering characteristics of nearest 177 neighbouring atoms. There is no sharp peak at the rising edge, also known as the 178 whiteline (WL), indicating that the Ag d band is full. Metals with partially filled d bands 179 always exhibit an intense resonance historically called whiteline. The oscillations in the 180 spectra at increasing energy above the threshold (labeled II to V) are due to the multiple 181 and single scattering of the photoelectrons by the neighboring Ag atoms. The oscillation 182 patterns within the $\mathrm{L}_{3}$-edge XANES of the alloy standard and the A1-3 specimen are 183 indicative of a face centered cubic (fcc) structure [13].

184 Region $\mathrm{I}$ is the WL region assigned to the excitation of a $2 \mathrm{p}_{3 / 2}$ electron to unoccupied 185 bands just above the Fermi level, which possess both s and d character. The absorption is 186 weak because the $5 \mathrm{~d}$ bands are full in $\mathrm{Ag}$ metal, although the presence of some $\mathrm{d}$ 187 character is possible due to s-d hybridization. Regions II - IV can be viewed as multiple 188 scattering resonances given rise by the fcc environment of the Ag atom [13]. The 189 intensity of peak II increases from $\mathrm{Ag}_{5} \mathrm{Au}_{95}$ to pure $\mathrm{Ag}$ while the magnitude of region $\mathrm{V}$ 190 decreases (Figure 3A). At peak V and beyond, the electron energy is sufficiently high to 191 be considered as an extended X-ray absorption fine structure (EXAFS) oscillation where 192 single scattering begins to prevail as it examines the region between $150-2,000 \mathrm{eV}$. 
The position of the oscillations (positions of the resonance relative to the threshold) can be used to qualitatively infer the degree of $\mathrm{Ag}$-Au lattice distortion in the fcc structure. Gold and silver are comparable in size Ag [16] but different in backscattering amplitude and phase, introducing are slight distortions in XANES oscillations in alloys

197 compared to pure Ag. These multiple scattering events are larger in $\mathrm{Au}$ than $\mathrm{Ag}$ and 198 therefore have different $k$ dependence, $k$ being the wavenumber of the photoelectron 199 relating to the square root of the photon energy above the threshold [17]. These factors will influence the oscillations in the XANES spectrum.

201 The transition in the $\mathrm{Ag}_{2} \mathrm{~S}$ spectrum is due to a $\mathrm{Ag} 2 \mathrm{p}_{3 / 2}$ electron being excited to 202 unoccupied bands above the Fermi level, whose bands possess both $\mathrm{s}$ and $\mathrm{d}$ character. 203 The $\mathrm{Ag}_{2} \mathrm{~S}$ on the daguerreotype plate surface is a combination of procedural and 204 environmental products. Due to the overriding signal of the Ag substrate [18], the $\mathrm{Ag} \mathrm{L}_{3}$ 205 edge is not appropriate for comparison to the $\mathrm{Ag}_{2} \mathrm{~S}$ and $\mathrm{AgCl}$ standards, which bear no 206 resemblance to the daguerreotype regions A1-3.

207 The XANES of all the daguerreotype samples areas, A1 (dark), A2 (mid-tone) and A3 208 (bright), look similar to that of pure $\mathrm{Ag}$ and $\mathrm{Ag}_{95} \mathrm{Au}_{5}$ while noticeably different from the 209 alloys with dilute Ag in Au. While the A1-3 oscillations of region $\mathrm{V}$ have shifted to 210 slightly higher energy, indicative of varying Ag-Au neighborhood in daguerreian alloy in 211 comparison to the alloy standards, the magnitude of regions I, II, and V for A1-3 falls 212 between $\mathrm{Ag}$ and $\mathrm{Ag}_{95} \mathrm{Au}_{5}$, indicating that the alloy present within the daguerreotype 213 surface and near surface region has between $95-100 \%$ atomic percent Ag and $5-0 \%$ 214 atomic percent Au. Based on the diffusion coefficient of $10^{-13} \mathrm{~cm}^{2} / \mathrm{s}$ calculated for Au 215 into $\mathrm{Ag}$ and $\mathrm{Ag}$ into $\mathrm{Au}$ on a historic daguerreotype plate [19], the observed alloy 216 percentage of relatively low levels of Au may be partly due to the relatively slow inter- 
217 diffusion for $\mathrm{Ag}$ and $\mathrm{Au}$. However, as the degree of gilding is operator dependent, it is

218 difficult to determine if the degree of alloying is due to the age of the plate or the

219 independent recipe and methodology of the producer. Due to the dominant Ag signal in

220 samples A1-3, the majority of information regarding the subtle variations in chemical

221 structure on the daguerreian surface will come from $\mathrm{Au}, \mathrm{Hg}$, and $\mathrm{S}$, which are discussed

222 below.

\section{$223 \quad 3.2$ Gold}

224 The $\mathrm{Au} \mathrm{L}_{3}$-edge XANES of regions A1-3 and alloy standards are shown in Figure 4.

225 Gold is the most electronegative metallic element having a Pauling scale value of 2.54, 226 compared to Ag 1.93 [20] and, therefore, it is expected that Au will gain charge from Ag 227 upon alloy formation. It is also expected that $\mathrm{Au}$ upon deposition on $\mathrm{Ag}$ will form $\mathrm{Au}-\mathrm{Ag}$ 228 alloys. Previous analysis of the $\mathrm{Au} \mathrm{L}_{3}$ edge whiteline of $\mathrm{Au}-\mathrm{Ag}$ alloys establishes that the 229 WL intensity increases upon dilution of $\mathrm{Au}$ in Ag. This result indicates that $\mathrm{Au}$ in fact 230 gains $\mathrm{s}$ charge, $\Delta \mathrm{n}_{\mathrm{s}}>0$ and loses $5 \mathrm{~d}$ charge, $\Delta \mathrm{n}_{\mathrm{d}}<0$ upon dilution in Ag but the overall 231 charge flow, $\delta$, though small, is from $\mathrm{Ag}$ to $\mathrm{Au}$, in line with electronegativity 232 considerations [21]. The $\mathrm{Au} \mathrm{L}_{3}$-edge jump appears at $11,919 \mathrm{eV}$ (region I) and 233 corresponds to the electronic transition from the $2 \mathrm{p}_{3 / 2}$ core level to the vacant $5 \mathrm{~d}_{5 / 2}$ and $2345 \mathrm{~d}_{3 / 2}$ states just above the Fermi level. A gradual increase in the area under the curve at 235 regions $\mathrm{I}$ from pure $\mathrm{Au}$ to the $\mathrm{Ag}_{95} \mathrm{Au}_{5}$ alloy is indicative of relatively more vacant $2365 \mathrm{~d}_{5 / 2,3 / 2}$ states (Figure 5). The resonances in regions II and III arises from the electron 237 transitions to unoccupied densities of states above the Fermi level (multiple scattering). 238 Peaks at (IV) and beyond are EXAFS arising from bound-to-continuum transitions 239 modulated by single backscattering of neighboring atoms. The fact that the XANES and 240 EXAFS look more Au-Ag alloy like than that of the pure Au indicates that Au-Ag alloy 
241 is formed. A closer inspection of region $\mathrm{V}$ reveals that the Au in A1-3 is similar to those

242 alloy standards with compositions between $\mathrm{Ag}_{75} \mathrm{Au}_{25}$ and $\mathrm{Ag}_{95} \mathrm{Au}_{5}$ [22].

243 From Figure 5, information can be gained by closely inspecting the edge jump. It 244 should be noted that although $\mathrm{Au}$ has a full d-band, s-d hybridization and electron 245 redistribution upon alloying with $\mathrm{Ag}$ will introduce unoccupied densities of state of $5 \mathrm{~d}$ 246 character at the Fermi level. From Figure 5A we see that as the relative concentration of $247 \mathrm{Au}$ compared to $\mathrm{Ag}$ is greatly reduced, the XANES data reveal more information 248 regarding the degree of alloying in the daguerreotype plate. The whiteline region shows 249 an increase in intensity hence an increase in the unoccupied density of $\mathrm{d}$ states. This 250 observation indicates a d charge transfer from $\mathrm{Au}$ to Ag upon dilution. Now, examining 251 the daguerreotype regions, $\mathrm{A} 2$ and $\mathrm{A} 3$ in Fig. 5B have the same magnitude and 252 oscillation of peaks I and II with intensity differences arising in peaks II and IV. This is 253 due to similar particle characteristics and composition in these two regions (A2 being a 254 midtone and A3 being a bright region). Relative to pure Au, an increased area under the 255 WL at peak I is indicative of proportionally less $5 \mathrm{~d}$ charge (i.e. dilution). This is more 256 prominent in region A1, suggesting that the greatest degree of alloying occurs in shadow 257 regions and supports the notion that an $\mathrm{Ag}-\mathrm{Au}$ alloy forms in the subsurface of the 258 daguerreotype plate. Shadow regions contain few or no image particles and thus enable 259 an increased amount of $\mathrm{Au}$ to diffuse into the subsurface, thereby allowing for the 260 relative enrichment of $\mathrm{Au}$ in the $\mathrm{Au}-\mathrm{Ag}$ alloy in this region of the daguerreian plate. This 261 is the result of simultaneous diffusion of $\mathrm{Au}$ into the $\mathrm{Ag}$ substrate and $\mathrm{Ag}$ into the $\mathrm{Au}$ 262 adlayer [19].

263 In comparison to the alloy standards, the normalized $\mu(\mathrm{E})$ spectra from daguerreotype 264 areas A1-3 were subjected to linear combination fitting (LCF). Analyses were conducted 
265 over an energy range of $-20 \mathrm{eV}$ below and $+40 \mathrm{eV}$ above the edge, thereby semi-

266 quantitatively fitting the alloy standards to peaks I, II, and III. Region A1 revealed that

267 alloy standards $\mathrm{Ag}_{95} \mathrm{Au}_{5}$ and $\mathrm{Ag}_{75} \mathrm{Au}_{25}$ were the primary contributors to the spectrum,

268 having weight percent (at. \%) values of 24.9 and 75.1 for $\operatorname{Ag}_{75} \mathrm{Au}_{25}$ and $\mathrm{Ag}_{95} \mathrm{Au}_{5}$,

269 respectively. A similar result was observed in region $\mathrm{A} 2$, which contained $\mathrm{Ag}_{75} \mathrm{Au}_{25}$ and

$270 \mathrm{Ag}_{95} \mathrm{Au}_{5}$ at. \% values of 27.0 and 73.0, respectively. While the LCF curves (not shown)

271 are a very good fit to the A1 and A2 spectra, it is expected that other Ag-Au alloys

272 composition, which are comprised of at. \% values between 25 and 5 for $\mathrm{Au}$ and 75 and

27395 for $\mathrm{Ag}$, are present. Therefore, given the spot size of the area analyzed and the

274 diffusion mechanism, a good estimation of the average alloy composition present within

275 the shadow and midtown regions is the average of these two standards: $\mathrm{Ag}_{90} \mathrm{Au}_{10}$.

276 While regions $\mathrm{A} 1$ and $\mathrm{A} 2$ only exhibit contributions from $\mathrm{Ag}_{95} \mathrm{Au}_{5}$ and $\mathrm{Ag}_{75} \mathrm{Au}_{25}$ (i.e.,

277 all other alloys had an at. \% of 0 ), region $\mathrm{A} 3$ had contributions from $\mathrm{Ag}_{50} \mathrm{Au}_{50}, \mathrm{Ag}_{75} \mathrm{Au}_{25}$,

278 and $\mathrm{Ag}_{95} \mathrm{Au}_{5}$, with at. \% of $17.7\left(\mathrm{Ag}_{50} \mathrm{Au}_{50}\right), 27.7\left(\mathrm{Ag}_{75} \mathrm{Au}_{25}\right)$, and $54.6\left(\mathrm{Ag}_{95} \mathrm{Au}_{5}\right)$. This

279 LCF curve (not shown) is a very good fit to the A3 spectrum. Again, following the

280 simultaneous diffusion mechanism of $\mathrm{Ag}$ into $\mathrm{Au}$ and $\mathrm{Au}$ into $\mathrm{Ag}$, the proposed alloy for

281 the highlight region is an average of the three contributing standards, consequently

$282 \mathrm{Ag}_{73} \mathrm{Au}_{27}$. While these calculations are semi-quantitative at best, it does indicate a

283 significant increase in $\mathrm{Au}$ content hence contributing to its lighter appearance. The

284 amount of $\mathrm{Au}$ in the Ag-Au alloy increases from dark (A1) to highlight (A3) regions,

285 emphasizing that alloying occurs on the image particles as well as with depth on the

286 daguerreian plate, hence region A3 (highlight region) having the alloys with higher Au

287 content. 
288 It should be noted that when $\mathrm{Au}$ is introduced to the daguerreotype system, the gold289 chloride-sodium thiosulfate solution is poured from above and covers the entire plate. 290 From this, we assume an even amount of $\mathrm{Au}$ is present on all regions of the 291 daguerreotype. Regions of high image particle density (bright regions) will have a 292 relatively greater amount of $\mathrm{Au}$ on the surface of the plate due to diffusion limitations 293 from the increased surface area of the image particles. Conversely, in dark regions where 294 few/none image particles are observed, there is still an equal amount of $\mathrm{Au}$ but as a 295 greater degree of diffusion is permitted to occur, there is relatively less Au on the surface 296 and greater amount of subsurface alloying. Therefore the amount of total Au on the 297 daguerreotype does not change from bright to dark regions, but the amount of Au in the 298 Au-Ag alloy (degree of alloying) does.

\section{$299 \quad 3.3$ Mercury}

300 The $\mathrm{Hg} \mathrm{L}_{3}$-edge spectra are displayed in Figure 6. The absence of a whiteline indicates 301 the deficiency of $\mathrm{d}$ vacancies above the Fermi level of $\mathrm{Hg} \mathrm{d}$ character (s character is 302 itinerant), suggesting the existence of metallic phase $\mathrm{Hg}$. Peak positions of regions I-IV 303 confirm the presence of an $\mathrm{Hg}$-Ag amalgam particle $[2,12,19]$, reported to possess 10.5 304 atomic percent $\mathrm{Hg}$ [19]. Peak III, IV, and the subsequent EXAFS oscillations also show 305 characteristics consistent with the Hg-Ag interaction [12]. The EXAFS oscillation varies 306 slightly from region to region and has multiple beatings indicating that $\mathrm{Hg}$ has both $\mathrm{Hg}$ 307 and Ag neighbor. The periodicity of the oscillations suggests that the local environment 308 varies somewhat from $\mathrm{A} 1$ to $\mathrm{A} 3$. The whiteline of $\mathrm{A} 1-3$ has no resemblance to $\mathrm{HgO}$ or $309 \mathrm{HgCl}_{2}$ as peak I $(12,288 \mathrm{eV})$ occurs as a shoulder opposed to a separate oscillation. 310 Furthermore, the energy differences between peaks I and II in A1-3 first derivative 311 spectra (not shown) are greater than that reported by Rajan et al. for $\alpha / \beta-\mathrm{HgS}$ [23]. It is 
312 unclear from these spectra if there is any variation in $\mathrm{Hg}-\mathrm{Ag}$ alloying across the three 313 examined regions. In all likelihood, a variety of $\mathrm{Hg}-\mathrm{Ag}$ structures are present on the

314 surface as suggest by Ravines et. al. [2].

$315 \quad 3.4$ Sulfur

316 The sulfur K-edge (Figure 7), which arises from an electron being excited from a 1s 317 orbital to a $3 p$ orbital, was recorded at $2,469.5 \mathrm{eV}$, indicative of transition-meal sulfides, 318 such as $\mathrm{Ag}_{2} \mathrm{~S}$ [24]. Li et al [25] have conducted extensive analysis of the edge peak shift 319 as a function of oxidation states, which spans 10-12 eV and includes sulfides (2-), native $320 \mathrm{~S}(0)$, sulfite $(4+)$, and sulfates $(6+)$. The location of the K-edge from the daguerreian test 321 plate is indicative of a metal sulfide interaction, which becomes increasingly complicated 322 upon p-d hybridization between $\mathrm{S}$ antibonding and metal $3 \mathrm{~d}$ states. This suggests that the $323 \mathrm{~S} \mathrm{p} \pi^{*}$ orbital is directly involved in the covalent Ag-S interaction [26]. This metal-sulfur 324 bond is confirmed by the double feature of peak I that are characteristic of transition 325 metal sulfur interaction [27]. What differs across A1-3 is the distinction of this peak I, 326 which is greatest in A2 while A1 and A3 appear as a shoulder. The location of the 327 electronic transition of peak III $(2,482 \mathrm{eV})$ is due to sulfates in the form of $\mathrm{Ag}_{2} \mathrm{SO}_{4}$ [26, 328 28] or less likely an organic sulfonate species [29]; the amplitude of this peak decreases 329 from $\mathrm{A} 2, \mathrm{~A} 1$ to $\mathrm{A} 3$. Adsorption of $\mathrm{SO}_{2}$ from ambient atmosphere on sliver surfaces has 330 been previously reported [30]. A shift in peak position by approximately $-0.2 \mathrm{eV}$ for $\mathrm{A} 2$ 331 and A3 suggests a different chemical environment in these regions. This may be the 332 result of an $\mathrm{Ag}_{2} \mathrm{~S}$-nanoparitcle interaction in these relatively brighter regions [31]. The 333 broad nature of the peak at $\sim 2,500 \mathrm{eV}$ arises from the cumulative multiple scattering 334 contributions of all sulfur species [32]. Work previously conducted by Outka et al. [32] 
335 suggests that $\mathrm{Ag}$ is incapable of reducing $\mathrm{S}$; any $\mathrm{Ag}_{2} \mathrm{~S}$ present is atmospheric in origin or

336 a consequence of the gold-chloride-sodium thiosulfate solution used when gilding.

\section{Conclusions}

338 Synchrotron-based X-ray absorption spectroscopy proved to be a valuable technique to 339 the study of daguerreotypes; no physical or chemical variation was observed on the 340 surface after exposure to X-rays. This study provides information pertinent to the 341 advancement of the chemical understanding of historic plates. Firstly, the $\mathrm{Ag} \mathrm{L}_{3}$-edge 342 showed that the image particles on the surface form an alloy with a face centered cubic 343 structure. The degree of $\mathrm{Au}$ diffusion into the $\mathrm{Ag}$ plate differed across the surface. 344 Secondly, while $\mathrm{Au} \mathrm{L}_{3}$-edge examination revealed the shadow region (A1) to have the 345 greatest degree of Ag-Au alloying, the highlight region (A3) possessed the greatest Au 346 surface concentration and variation in alloys composition. The relative amount of $\mathrm{Au}$ in 347 the Ag-Au alloy also varies between different tonal regions on the daguerreian surface. 348 As estimated from the $\mathrm{Au}$ XANES analysis, an average alloy composition of $\mathrm{Ag}_{90} \mathrm{Au}_{10}$ 349 was determined for the shadow and midtone regions while the highlight region suggested 350 an average alloy composition of $\mathrm{Ag}_{73} \mathrm{Au}_{27}$. This variation in the $\mathrm{Ag}$ - $\mathrm{Au}$ alloy across 351 bright to shadow regions should be considered before conservation treatments are applied 352 as each region of the plate will react differently to the proposed method. Thirdly, 353 examination of the $\mathrm{Hg} \mathrm{L}_{3}$-edge suggests that metallic $\mathrm{Hg}$ was amalgamated with the $\mathrm{Ag}$ 354 image particles. Finally, the S K-edge revealed the presence of sulfates and sulfides on 355 the surface, in the form of $\mathrm{Ag}_{2} \mathrm{~S}$ and $\mathrm{Ag}_{2} \mathrm{SO}_{4}$, respectively. Data may suggest the 356 presence of $\mathrm{Ag}_{2} \mathrm{~S}$-nanoparticle interactions in brighter regions as well as organic 357 sulfonate species across all regions of the sample. Organic sulfur may be residue from the 358 final wash step in the test plate's production. Production residue may serve as the primary 
359 source of chemical deterioration on the daguerreian surface. This work highlights the 360 capabilities of synchrotron-based absorption spectroscopy in the analysis of the 361 daguerreotype surface.

\section{Acknowledgements}

363 This research was supported by the National Science and Engineering Research Council 364 of Canada, the Canadian Foundation for Innovation, Canada Research Chairs (TKS) and 365 the Ontario Ministry of Innovation. Further support for interdisciplinary research was 366 provided by The Dean's Office at The University of Western Ontario, Faculty of Science.

367 Synchrotron experiments were performed at the Canadian Light Source, which is 368 supported by NSERC, NRC, CIHR and the University of Saskatchewan.

\section{References}

[1] Da Silva, E.; Robinson, M.; Evans, C.; Pejovic-Milic, A.; Heyd, D.F. J. Anal. Atom. Spectrosc. 2010, 25, 654-661.

[2] Ravines, P.; Li, L.; McElroy, R. J. Imaging Sci. Technol. 2016, 10, 30504-1 - 3050410.

[3] Barger, S.M.; White, W.B. The daguerreotype: nineteenth century technology and modern science; Smithsonian Institution Press, Washington, 1991, a: pp. 120, b: pp. 162.

[4] Ravines, P; Wiegandt, R.; Wichern, C.M. Surface Eng. 2008, 24, 138-146.

[5] Barger, S.M.; Krishnaswamy, S.V.; Messier, R. J. Am. Conserv. 1982, 22, 13-24.

[6] Centeno, S.; Schulte, F.; Kennedy, N.; Schrott, A. Appl. Phys. A. 2011, 105, 55-63.

[7] Barger, S.M.; Messier, R.; White, W.B. Photogr. Sci. Eng. 1982, 26, 285-291.

[8] Ravines, P. Am. Lab. 2010, 42, 20-25. 
[9] Anglos, D.; Melesanaki, K.; Zafiropulos, V.; Gresalfi, M.J.; Miller, J.C. Appl.

Spectrosc. 2002, 56, 423-432.

[10] Hogan, D.L.; Golovlev, V.V.; Gresalfi, Chaney, J.A.; Feigerie, C.S.; Miller, J.C.;

Romer, G.; Messier, P. Appl Spectrosc. 1999, 53, 1161-1168.

[11] S. D. Humphrey, American Hand Book of the Daguerreotype: Giving the Most Approved and Convenient Methods for Preparing the Chemicals, and the Combinations Used in the Art. Containing the Daguerreotype, Electrotype, and Various Other Processes Employed in Taking Heliographic Impression, $5^{\text {th }}$ Eds.; S. D. Humphrey, New York, 1858.

[12] George, G.N.; Singh, S.P.; Hoover, J.; Pickering, I. J. Chem. Res. Toxicol. 2009, 22, 1761-1764.

[13] Bzowski, A.; Sham, T.K.; Yiu, Y.M. Anal. Review B. 1994, 49, 13776-13779.

[14] Ravel, B.; Newville, M. J. Synchrotron Radiat. 2005, 12, 537-541.

[15] Ravel, B. Athena User's Guide. http://cars9.uchicago.edu/ ravel/software/exafs/. (accessed 10 September 2014).

[16] Hammond, C.R. Handbook of Chemistry and Physics; $81^{\text {st }}$ Eds.; CRC press, New York, 2004; pp. 115.

[17] Newville, M. Fundamentals of XAFS; $2^{\text {nd }}$ Eds.; University of Chicago, Chicago, 2004; pp. 7.

[18] Behrens, P.; Aßmann, S.; Bilow, U.; Linke, C.; Jansen, M. Z. Anorg Allg Chem. 1999, 625,111-116.

[19] Marquis, E.A.; Chen, Y.; Kohanek, J.; Dong, Y.; Centeno, S.A. Corros Sci, 2015, $94,438-444$. 
[20] Pauling, L. The Nature of the Chemical Bond, $3^{\text {rd }}$ Eds.; Cornell University Press, Ithaca, 1960; pp. 88 .

[21] Sham, T.K.; Ward, M.J.; Murphy, M.W.; Liu, L.J.; Han, W.Q. J. Phys.: Conf. Ser. 2013, 425, 092006.

[22] Tyson, C.C; Bzowski, A.; Kristof, P.; Kuhn, M.; Sammynaiken, R.; Sham, T.K. Phy. Rev. B, 1992, 45, 8924-8928.

[23] Rajan, M.; Darrow, J.; Hua, M.; Barnett, B.; Mendoza, M.; Greenfield, B.K.;

Andrews, J.C. Environ. Sci. Technol. 2008, 43, 7397-7402.

[24] Shimizu, K.; Kobayashi, N.; Satsuma, A.; Kojima, T.; Satokawa, S. J. Phys. Chem. B. 2006, 110, 22570-22576.

[25] Li, D.; Bancroft, M.; Kasrai, M.; Fleet, M.E.; Feng, X.; Tan, K. Can. Mineral. 1995, $33,949-960$.

[26] Fleet, M.E. Can. Min. 2005, 43, 1811-1838.

[27] Hullebusch, E.; Rossano, S.; Farges, F.; Lenz, M.; Labanowski, J.; Lagarde, P.;

Flank, A-M.; Lens, P. J. Phys: Conf. Ser. 2009, 190, 012184.

[28] Fors, Y.; Grudd, H.; Rindby, A.; Jalilehvand, F.; Sandström, M.; Cato, I.; Bommalm, L. Sci. Rep. 2014, 4, 4222-1 - 4222-6.

[29] Manceau, A.; Nagy, K.L. Geochim. Cosmochim. Acta. 2012, 99, 206-223.

[30] Outka, A.D.; Madix, R.J.; Fisher, G.B.; DiMaggio, C. J. Phys. Chem. 1986, 179, 124.

[31] Wang, P.; Menzies, N.W.; Lombi, E.; Sekine, R.; Blamey, F.P.C.; HernandezSoriano, M.C.; Cheng, M.; Kappen, P.; Peijnenburg, W.J.G.M.; Tang, C.; Kopittke, P.M. Nanotoxology. 2015, 9, 1041-1049. 
[32] Veronesi, G.; Koudouna, E.; Cotte, M.; Marin, F.L.; Quantock, A.J. Anal. Bioanal.

Chem. 2013, 405, 6613-6620.

\section{Tables}

Table 1 List of beamlines used for each element of interest.

\begin{tabular}{|l|l|l|}
\hline Element & Beamline & Edge(s) \\
\hline $\mathrm{Ag}$ & SXRMB (BM, $1.7-10 \mathrm{keV})($ daguerreotype plate, $\mathrm{Ag}$-Au alloy & \\
& standards, $\mathrm{AgCl}$, and $\mathrm{Ag}_{2} \mathrm{~S}$ standards) & L $_{3,2}$-edge \\
$\mathrm{Au}$ & VESPERS (BM, $6-30 \mathrm{keV})($ daguerreotype plate) & \\
\hline $\mathrm{Hg}$ & VESPERS (daguerreotype plate) & L $_{3,2}$-edge \\
\hline $\mathrm{S}$ & SXRMB (daguerreotype plate) & L $_{3}$-edge \\
\hline
\end{tabular}

Table 2 Series of silver-gold alloy standards [12].

\begin{tabular}{|l|c|c|}
\hline Name of Standard & Atomic Percentage of Silver & Atomic Percentage of Gold \\
\hline $\mathrm{Ag}$ & $100 \%$ & $0 \%$ \\
\hline $\mathrm{Ag}_{95} \mathrm{Au}_{5}$ & $95 \%$ & $5 \%$ \\
\hline $\mathrm{Ag}_{75} \mathrm{Au}_{25}$ & $75 \%$ & $25 \%$ \\
\hline $\mathrm{Ag}_{50} \mathrm{Au}_{50}$ & $50 \%$ & $50 \%$ \\
\hline $\mathrm{Ag}_{5} \mathrm{Au}_{95}$ & $5 \%$ & $95 \%$ \\
\hline $\mathrm{Au}$ & $0 \%$ & $100 \%$ \\
\hline
\end{tabular}




\section{Figure Captions}

Figure 1 Areas of interest, with accompanied labeling, examined from the daguerreotype test plate. Image taken with a single-lens reflex camera. (A1: dark region; A2: mid-tone region; A3: bright region)

Figure 2 Comparison of the $\mathrm{Ag} \mathrm{L}_{3}$-edge XANES of daguerreian test plate (A1, A2, A3) alloy standards $\left(\mathrm{Ag}_{95} \mathrm{Au}_{5}, \mathrm{Ag}_{5} \mathrm{Au}_{95}, \mathrm{Ag}_{50} \mathrm{Au}_{50}, \mathrm{Ag}_{75} \mathrm{Au}_{25}\right)$, and $\mathrm{Ag}_{2} \mathrm{~S}$

Figure 3 Comparison of (A) the $\mathrm{Ag} \mathrm{L}_{3}$-edge alloy standards and (B) of daguerreotype regions $\mathrm{A} 1, \mathrm{~A} 2, \mathrm{~A} 3$ against $\mathrm{Ag}_{95} \mathrm{Au}_{5}$ and $\mathrm{Ag}_{75} \mathrm{Au}_{25}$ standards

Figure $4 \mathrm{Au} \mathrm{L}_{3}$ XANES of daguerreian plate (A1, A2, A3) and alloy standards $\left(\mathrm{Ag}_{95} \mathrm{Au}_{5}\right.$, $\left.\mathrm{Ag}_{5} \mathrm{Au}_{95}, \mathrm{Ag}_{50} \mathrm{Au}_{50}, \mathrm{Ag}_{75} \mathrm{Au}_{25}, \mathrm{Au}\right)$. The dotted lines track the position of the resonances in pure $\mathrm{Au}$ and the solid line track the position of the oscillation in region $\mathrm{V}$ of the A1-3 XANES

Figure $5 \mathrm{Au} \mathrm{L}_{3}$-edge of (A) Au alloys and (B) daguerreotype regions A1-3 with Au, $\mathrm{Ag}_{75} \mathrm{Au}_{25}$, and $\mathrm{Ag}_{5} \mathrm{Au}_{95}$. Arrows indicate the relative increase of the area under the curve at relevant frequencies

Figure $6 \mathrm{Hg} \mathrm{L}_{3}$-edge of daguerreotype plate (A1, A2, A3) in comparison to elemental $\mathrm{Hg}$ standard

Figure 7 Sulfur K-edge of daguerreotype plates (A1, A2, A3) with $\mathrm{Ag}_{2} \mathrm{~S}$ standard 


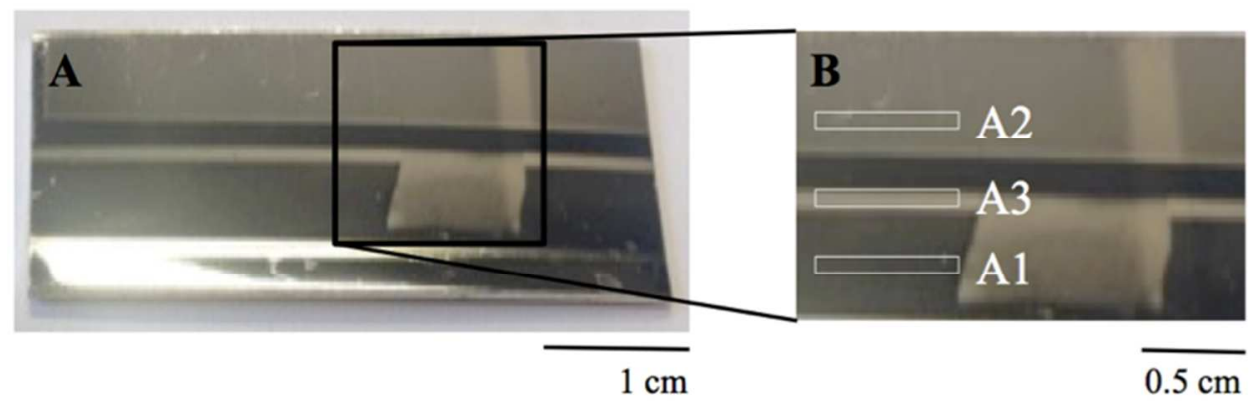

Figure 1 Areas of interest, with accompanied labeling, examined from the daguerreotype test plate. Image taken with a single-lens reflex camera. (A1: dark region; A2: mid-tone region; A3: bright region)

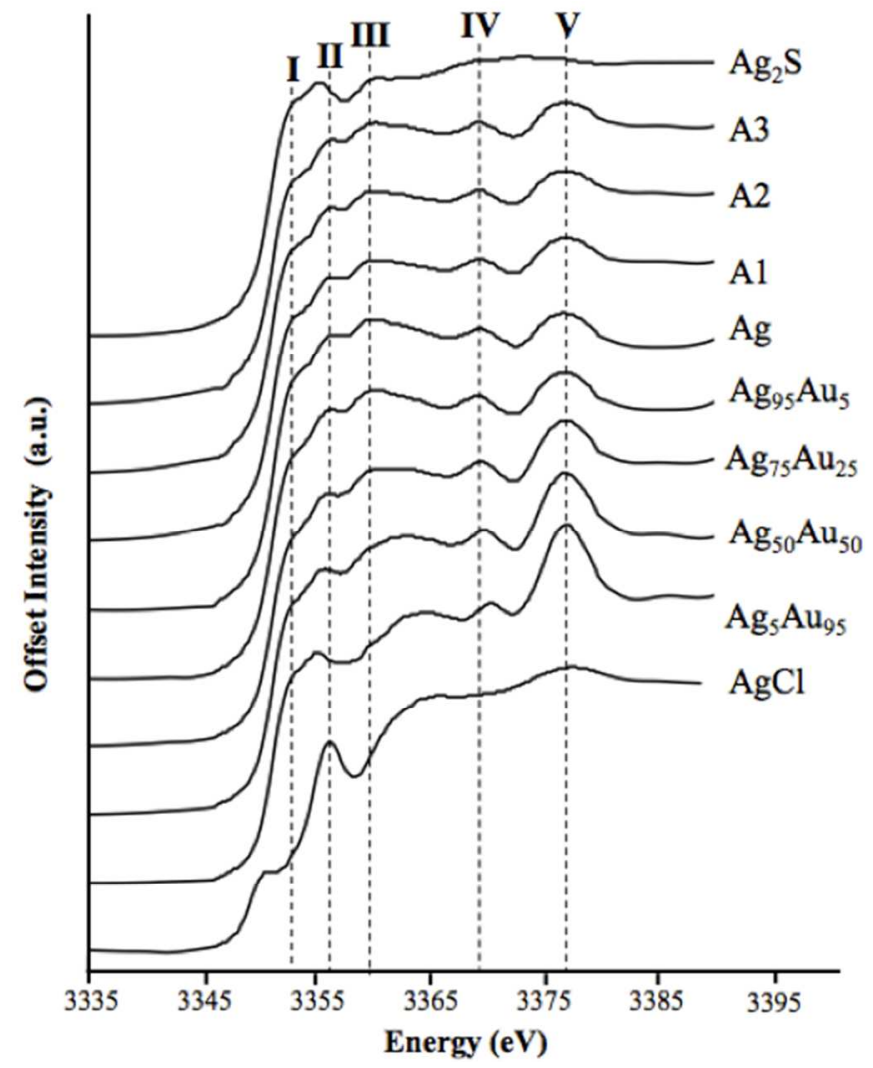

Figure 2 Comparison of the $\mathrm{Ag} \mathrm{L}_{3}$-edge XANES of daguerreian test plate (A1, A2, A3) alloy standards $\left(\mathrm{Ag}_{95} \mathrm{Au}_{5}, \mathrm{Ag}_{5} \mathrm{Au}_{95}, \mathrm{Ag}_{50} \mathrm{Au}_{50}, \mathrm{Ag}_{75} \mathrm{Au}_{25}\right)$, and $\mathrm{Ag}_{2} \mathrm{~S}$ 


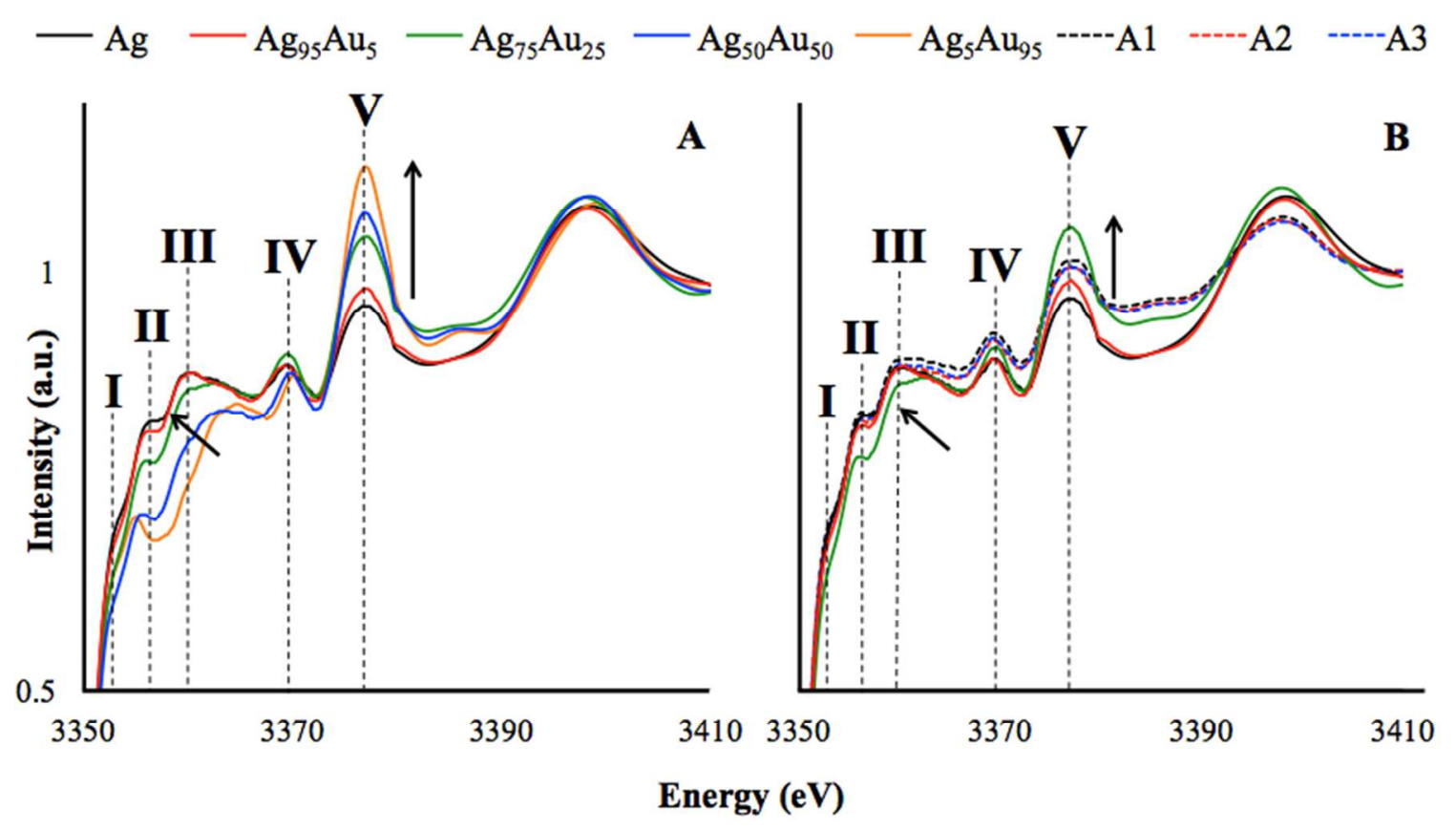

Figure 3 Comparison of (A) the $\mathrm{Ag} \mathrm{L}_{3}$-edge alloy standards and (B) of daguerreotype regions $\mathrm{A} 1, \mathrm{~A} 2, \mathrm{~A} 3$ against $\mathrm{Ag}_{95} \mathrm{Au}_{5}$ and $\mathrm{Ag}_{75} \mathrm{Au}_{25}$ standards 


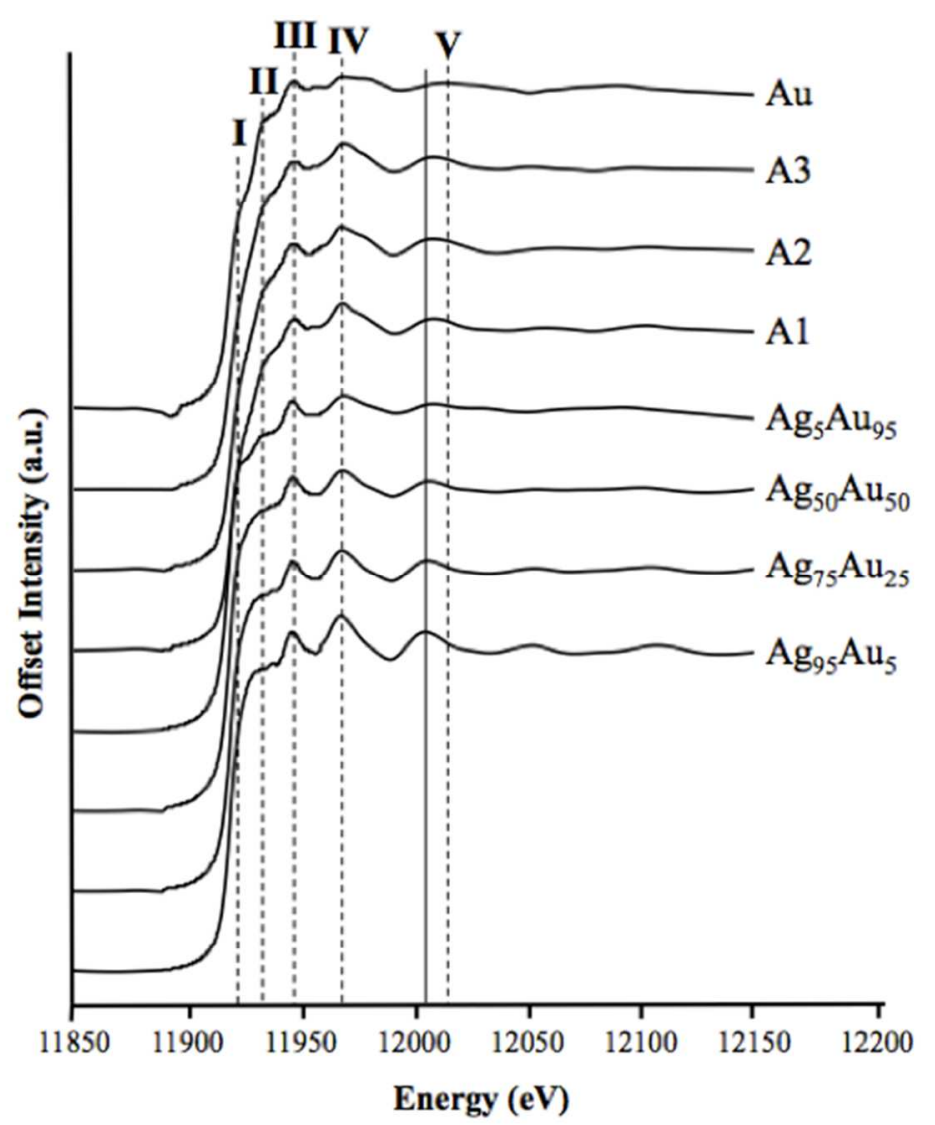

Figure $4 \mathrm{Au} \mathrm{L}_{3}$ XANES of daguerreian plate $(\mathrm{A} 1, \mathrm{~A} 2, \mathrm{~A} 3)$ and alloy standards $\left(\mathrm{Ag}_{95} \mathrm{Au}_{5}\right.$, $\left.\mathrm{Ag}_{5} \mathrm{Au}_{95}, \mathrm{Ag}_{50} \mathrm{Au}_{50}, \mathrm{Ag}_{75} \mathrm{Au}_{25}, \mathrm{Au}\right)$. The dotted lines track the position of the resonances in pure $\mathrm{Au}$ and the solid line track the position of the oscillation in region $\mathrm{V}$ of the A1-3 XANES 


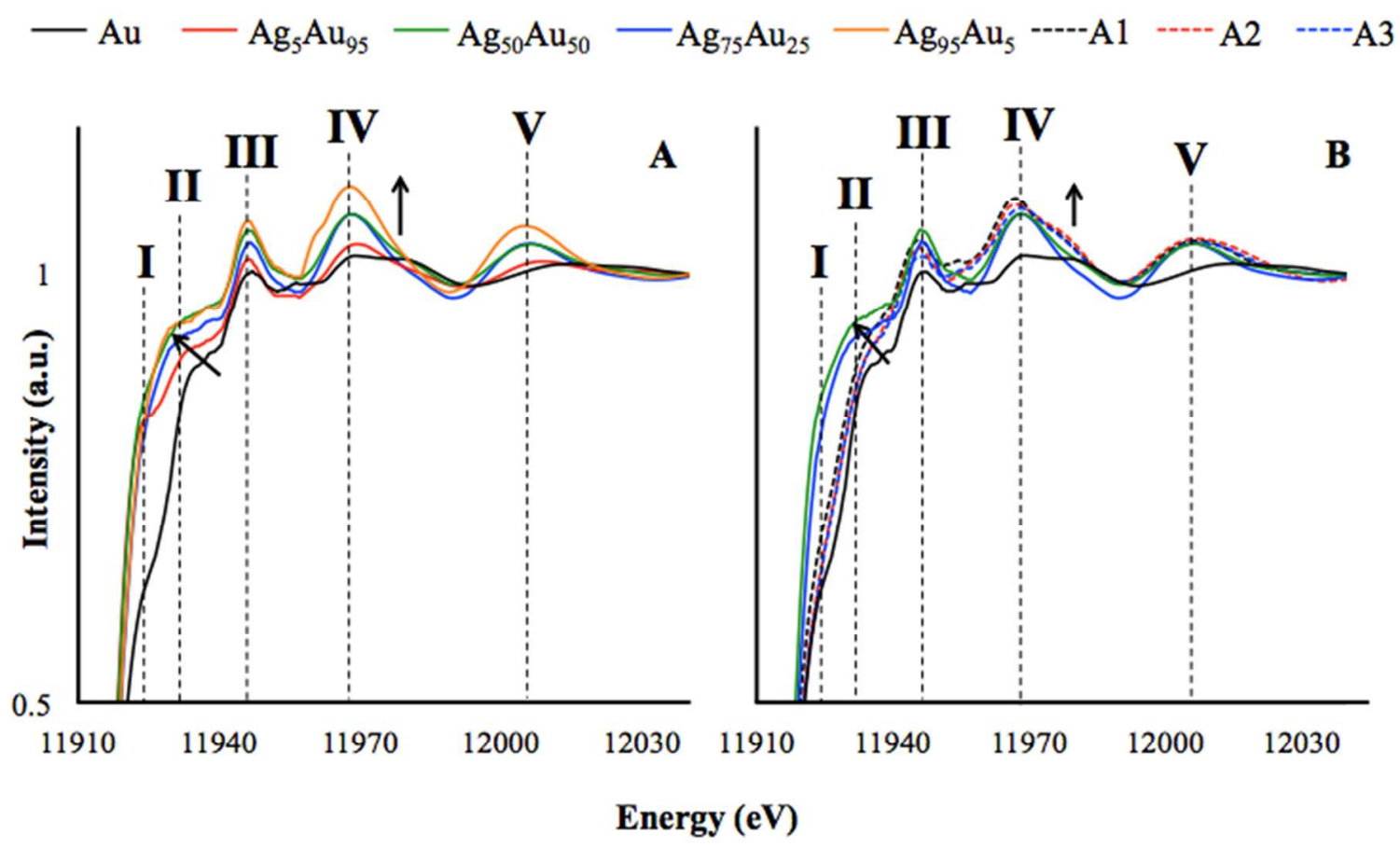

Figure $5 \mathrm{Au} \mathrm{L} \mathrm{L}_{3}$-edge of (A) Au alloys and (B) daguerreotype regions A1-3 with $\mathrm{Au}$, $\mathrm{Ag}_{75} \mathrm{Au}_{25}$, and $\mathrm{Ag}_{5} \mathrm{Au}_{95}$. Arrows indicate the relative increase of the area under the curve at relevant frequencies 


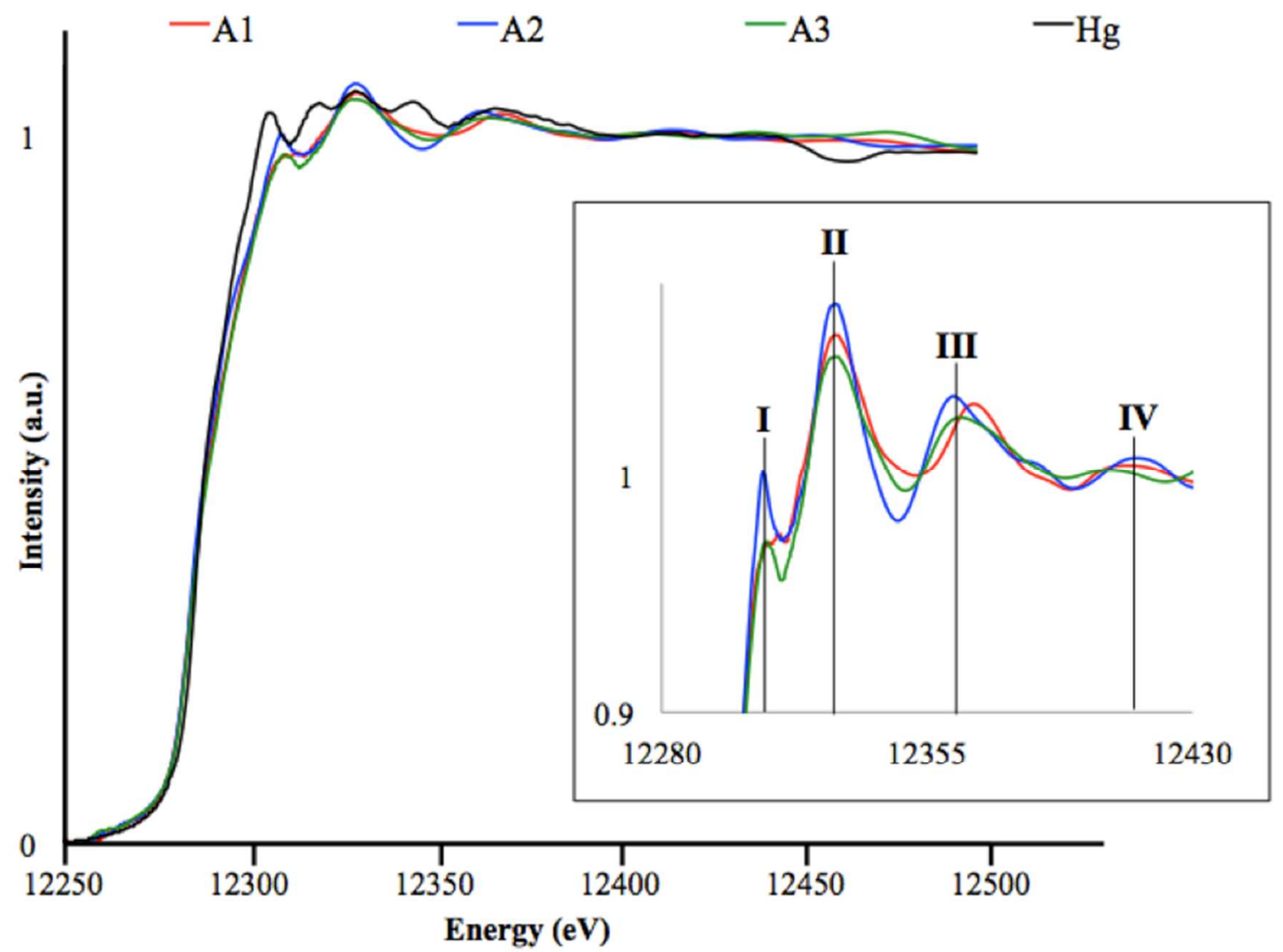

Figure $6 \mathrm{Hg} \mathrm{L}_{3}$-edge of daguerreotype plate (A1, A2, A3) in comparison to elemental $\mathrm{Hg}$ standard 




Figure 7 Sulfur K-edge of daguerreotype plates (A1, A2, A3) with $\mathrm{Ag}_{2} \mathrm{~S}$ standard 